\title{
Uma análise crítica do ensino de Física
}

\author{
MARCO ANTONIO MOREIRA ${ }^{\mathrm{I}}$
}

\section{Introdução}

A PESQUISA em ensino de Física no Brasil tem longa tradição e é reconhecida internacionalmente. Encontros nacionais de pesquisa em ensino de Física são realizados desde a década de 1980. A pós-graduação em ensino de Física também existe desde essa época, assim como revistas de pesquisa em ensino de Física ou em ensino de Ciências onde podem ser publicados artigos de pesquisa em várias áreas.

Além da pesquisa em ensino de Física, outras atividades como simpósios, oficinas, projetos, livros e demais materiais foram desenvolvidos desde o surgimento e consolidação de uma área de ensino de Física. Grandes professores pesquisadores e produtores de recursos instrucionais deixaram sua marca no ensino de Física no Brasil.

Paradoxalmente, no entanto, esse ensino está em crise. A carga horária semanal que chegou a 6 horas-aula por semana, hoje é de 2 ou menos. Aulas de laboratório praticamente não existem. Faltam professores de Física ${ }^{1}$ nas escolas e os que existem são obrigados a treinar os alunos para as provas, para as respostas corretas, ao invés de ensinar Física. A interdisciplinaridade e a transdisciplinaridade são confundidas com não disciplinaridade e tiram a identidade da Física. Os conteúdos curriculares não vão além da Mecânica Clássica e são abordados da maneira mais tradicional possível, totalmente centrada no professor, baseada no modelo de narrativa criticado por Finkel (1999), na educação bancária de Freire (2007), no comportamentalismo de Skinner (1972). O resultado desse ensino é que os alunos, em vez de desenvolverem uma predisposição para aprender Física, como seria esperado para uma aprendizagem significativa, geram uma indisposição tão forte que chegam a dizer, metaforicamente, que "odeiam" a Física.

\section{Mas por que tudo isso? Por que esse ensino?}

Certamente, são muitas as razões, das quais salienta-se, de imediato, a desvalorização da carreira docente na Educação Básica no Brasil. No discurso, a educação é sempre prioritária; na prática, as condições do trabalho, em muitos casos, são vergonhosas. Baixos salários, muitos alunos, elevada carga horária semanal, falta de apoio na formação continuada, currículos que não passam de uma lista de conteúdos a serem cumpridos, preparação dos alunos para a testagem. 
Não é o caso do Ensino Superior cujas condições de trabalho, em geral, são muito boas. Mas o ensino de Física nesse nível é tradicional, centrado no docente, na memorização de fórmulas a serem aplicadas na resolução de problemas conhecidos. Com esse ensino, os estudantes só querem passar e usar a regra "matéria passada matéria esquecida".

Mas aqui serão abordados, criticamente, apenas alguns aspectos do ensino de Física, na Educação Básica e Superior, na visão do autor, a partir de sua experiência como professor de Física, no Ensino Médio e no Superior, durante cinquenta anos, como coordenador de pós-graduação e orientador de muitas dissertações e teses em ensino de Física, como integrante de comissões nacionais e internacionais em educação e ensino, como editor de revistas em ensino de Física e de ciências de modo geral.

\section{A pesquisa básica}

O impacto da pesquisa básica em ensino de Física na sala de aulas de Física é muito pequeno, praticamente nenhum. Os resultados dessa pesquisa são publicados em revistas destinadas a pesquisadores, aos pares. Professores não participam dessa pesquisa e não leem os artigos publicados nessas revistas. Algumas pesquisas são feitas na escola, na sala de aulas, mas apenas para gerar dados para uma dissertação, para uma tese, para um projeto específico. Uma vez feita a coleta de dados, nada muda no ensino de Física no contexto dessa coleta.

Professores não participam da pesquisa em ensino de Física, não se sentem pesquisadores, não recebem apoio institucional para serem professores pesquisadores. Mas sem sua participação os resultados da pesquisa básica em ensino de Física nunca chegarão ao ensino de Física propriamente dito. Um paradoxo!

Outro aspecto crítico da pesquisa básica em ensino de Física é que muitas vezes essa pesquisa não tem Física. São muitas as publicações nessa área que estariam mais bem situadas na educação, na psicologia, na sociologia, pois nelas a Física parece irrelevante.

\section{A pesquisa aplicada}

Diferentemente da pesquisa básica, dirigida à produção de conhecimentos, a pesquisa aplicada é focada em questões práticas que buscam prover soluções relativamente imediatas. Em princípio, essa pesquisa poderia contribuir muito para melhorar o ensino de Física na medida em que se ocupasse de problemas específicos desse ensino e envolvesse professores de Física.

No entanto, essa pesquisa estaria mais perto da produção técnica, por exemplo, de recursos instrucionais como textos de apoio, aplicativos, sequências didáticas, materiais de laboratório. Porém, no contexto acadêmico e na pós-graduação, a produção técnica vale bem menos do que a produção dita intelectual, ou seja, os papers publicados em revistas bem indexadas.

\section{A pesquisa translacional}

O termo translacional sugere que resultados de pesquisa existem, estão 
à mão, mas devem ser traduzidos à linguagem da prática. Como foi dito antes, o impacto da pesquisa básica no ensino de Física é muito pequeno, quase inexistente. Mas os resultados dessa pesquisa estão publicados e muitos deles poderiam ser trazidos à sala de aulas, ou seja, transladados à prática ao invés de ficarem restritos à academia. Nessa translação a participação dos professores seria indispensável, porém não há apoio institucional para isso.

\section{As publicações}

Conhecimentos produzidos e não publicados não existem. A publicação é importante para o crescimento de qualquer área, mas, hoje, vive-se uma cultura publicacionista na qual o que vale são os artigos publicados em revistas "bem indexadas" e com alto "factor de impacto". A publicação está trivializada, comercializada e até mesmo predatória. Na ciência, esse publicacionismo está acabando com a criatividade, porque pesquisadores não se arriscam em projetos que podem não gerar papers, e está originando uma falsa ciência, pois muitos resultados publicados não são reproduzíveis.

Nas universidades, os professores são avaliados por suas publicações no contexto dessa cultura publicacionista. Seu ensino recebe pouca ou nenhuma atenção, mas são eles que participam muito da formação de professores para a escola. Na Física também é assim. O que importa são as publicações em revistas de "alto impacto". O ensino é obrigação e é conduzido de um modo tão tradicional que é pior do que ineficiente, é anticientífico (Wieman, 2013).

O que esperar de professores de Física da Educação Básica que são formados em uma abordagem anticientífica? Não muito, infelizmente. Provavelmente ensinarão do modo como foram ensinados. O ensino de Física (e de STEM: Ciência, Tecnologia, Engenharia e Matemática) deve ser modificado radicalmente e ser valorizado no contexto universitário.

\section{A testagem}

Outro sério problema para do ensino de Física, e de outras disciplinas, é a testagem, ou seja, a preparação para a testagem. Professores devem preparar os alunos para a testagem, para as provas, para as respostas corretas a serem reproduzidas em exames locais, nacionais e internacionais. Internacionalmente já está consagrado o termo teaching for testing. Um absurdo, os professores são treinadores e as escolas são centros de treinamento. As melhores escolas são aquelas que aprovam mais alunos nos testes. Uma visão comportamentalista, mercadológica, massificadora. Todos os estudantes devem ser treinados para "passarem" nas mesmas provas nacionais e internacionais. Professores que não ensinam para a testagem têm a atenção chamada pela direção da escola. Na Física, os alunos sofrem esse ensino para a testagem, passam nos testes, mas chegam à universidade como se não tivessem estudado Física no Ensino Médio. O mesmo ocorre com outras disciplinas. O ensino para a testagem não é ensino, é só treinamento para respostas de curto prazo. 


\section{As Tecnologias de Informação e Comunicação (TIC)}

É óbvio que, no contexto atual, as Tecnologias de Informação e Comunicação (TIC) deveriam permear o ensino de Física. Mas isso não acontece. Como já foi destacado, esse ensino é o mesmo de sempre: aulas expositivas e listas de problemas, quadro-de-giz (slides em PowerPoint é a mesma coisa), livro de texto único (ou apostila única), conteúdos desatualizados, aprendizagem mecânica ("decoreba") de fórmulas e respostas corretas.

Simulações computacionais, modelagem computacional, laboratórios virtuais deveriam estar naturalmente integrados ao ensino de Física no século XXI. Celulares também poderiam fazer parte dessa tecnologia que deveria permear o ensino de Física nos dias de hoje. Mas não é assim. É claro que a escola pode não ter a instrumentação necessária, mas a principal razão da não incorporação das TIC no ensino de Física na atualidade é o foco no treinamento para as provas, a ênfase nas "respostas corretas", no emprego de fórmulas para resolver problemas conhecidos. Isso é ensino de Física? Certamente não!

\section{A formação de professores}

Professores de Física são essenciais no ensino de Física. Mas suas condições de trabalho não lhes permitem buscar um verdadeiro ensino que conduza a uma verdadeira aprendizagem de Física. Por outro lado, sua formação em Física é fraca. Além de serem formados com o ensino tradicional, das aulas expositivas e listas de problemas, têm pouca Física na graduação, quase nada de Física moderna e contemporânea. No seu ensino, não passam da Física clássica, iniciando com a Cinemática, na qual os alunos começam a não gostar da Física.

Contudo, "mais Física" não significa mais conteúdos a serem decorados, memorizados mecanicamente. É preciso pensar em como ensinar esses conteúdos, é preciso dar atenção à didática específica, à transferência didática, a como abordar a Física de modo a despertar o interesse, a intencionalidade, a predisposição dos alunos, sem os quais a aprendizagem não será significativa, apenas mecânica para "passar",

A modelagem está na base da Física, conceitos são muito mais importantes do que fórmulas, aprender a perguntar em Física é mais importante do que saber respostas corretas. As melhores pesquisas decorrem das melhores perguntas. Tudo isso é Física e deveria estar na formação de professores. Mas não está, e o resultado é que a Física na Educação Básica, particularmente no Ensino Médio, é ensinada como se as teorias físicas fossem acabadas, como se as respostas às perguntas da Física fossem definitivas, como se os conceitos físicos fossem apenas definições. Isso não é Física, mas no ensino é abordada como se fosse.

\section{Física e cidadania}

A Física permeia a vida dos seres humanos. Está na base das Tecnologias de Informação e Comunicação, da engenharia, das técnicas de diagnósticos e tratamento usadas na medicina. A Física tem modelos e teorias que explicam 
grande parte do mundo físico em que vivemos. Biologia, Química, Neurociência e outras áreas científicas usam conceitos, princípios, modelos e teorias derivados da Física. Então, aprender Física é um direito do ser humano. Uma pedagogia libertadora deve resgatar o ser humano do senso comum, das interpretações ingênuas, do conformismo acrítico (Moreira, 2017)

A Física diz não ao senso comum, às interpretações ingênuas, à aceitação cega de modelos e teorias. As interpretações físicas nunca são definitivas. A Física está permanentemente buscando melhores modelos e teorias para explicar o Universo, desde perspectivas subatômicas até macrocósmicas.

Infelizmente, não é essa a Física ensinada na escola. A educação da qual o ensino de Física faz parte não estimula o ensino para a cidadania, sim para a testagem.

\section{As situações}

Outro problema de ensino de Física, relacionado à questão da cidadania, é o uso de situações-problema que façam sentido para os alunos. São situações que dão sentido aos conceitos e a conceitualização está no âmago desenvolvimento cognitivo (Vergnaud, 1990). As primeiras situações devem integrar o contexto do aluno. Novas situações devem ser introduzidas em níveis crescentes de complexidade. É um erro começar a ensinar sem usar situações que tenham sentido para os alunos, uma falha bastante comum no ensino de Física.

Esse erro é também cometido, em larga escala, no Ensino Superior no qual a Física, e também a Matemática, para futuros engenheiros, por exemplo, é ensinada sem usar situações da Engenharia. Chega-se ao absurdo de que estudantes de Engenharia não percebem a importância da Física para sua carreira e querem apenas "passar", verem-se "livres" da Física. O mesmo ocorre com a Matemática, particularmente no ensino de Cálculo. No entanto, Física e Matemática fazem parte do STEM (Science, Technology, Engineering, and Mathematics), uma tendência forte internacional que busca valorizar, estimular, redefinir o ensino e a integração de disciplinas dessa área.

Voltando aos conceitos, e parafraseando Vergnaud, poderíamos dizer que a conceitualização está no âmago da Física e na aprendizagem da Física. Portanto, as situações propostas e trabalhadas no ensino da Física devem fazer sentido para os alunos. É claro que situações abstratas, complexas, também devem ser trazidas ao ensino, mas no momento apropriado.

\section{Concluindo}

A proposta deste artigo foi a de fazer uma análise crítica de ensino de Física no Brasil, a partir da larga experiência do autor nesse ensino, em nível Médio e Superior, assim como em pesquisas, pós-graduações, coordenações, comissões, publicações, editorias nessa área.

Como foi destacado ao longo do texto, a Física está na base da tecnologia e o conhecimento físico é importante para a cidadania. A Física tem conceitos, 
perguntas, modelos, teorias que não são definitivos, mas que geram asserções de conhecimento altamente relevantes para o mundo de hoje. Além disso, aprender Física pode levar ao desenvolvimento de processos cognitivos, de uma consciência epistemológica e crítica.

No processo ensino-aprendizagem, em uma perspectiva humanista, pensamentos, sentimentos e ações estão integrados e essa integração pode ser positiva, levando ao engrandecimento do aprendiz, ou negativa, gerando uma indisposição em relação à matéria de ensino.

Infelizmente, o ensino de Física, de um modo geral, leva a uma integração negativa de pensamentos, sentimentos e ações, na qual os alunos não gostam da Física e, quando possível, evitam-na, uma vez que apenas desejam passar nas provas, repetindo nelas, mecanicamente, "o que foi dado em aula". Uma lásti$\mathrm{ma}$ !

O que fazer? Como sair dessa pedagogia opressora? Um grande desafio? Não se pode pensar em ensino e aprendizagem sem levar em conta o currículo e o contexto (meio social). Ensino (professor), aprendizagem (aluno), currículo (conhecimento) e contexto (meio social) são os chamados lugares comuns da educação (Schuwab, 1973) e estão interligados. Então, fica difícil, ou sem sentido, sugerir melhorias, mudanças no ensino buscando uma aprendizagem significativa, sem considerar integradamente esses lugares comuns da educação.

Apesar disso, conclui-se este trabalho com menção a alguns grandes desafios para o ensino da Física na educação contemporânea:

- Abandono do ensino tradicional, centrado no professor "dando a matéria", em favor de um ensino centrado no aluno, na aprendizagem ativa e significativa, na qual os alunos trabalham em pequenos grupos com a mediação do professor que os ajuda a aplicar conceitos e procedimentos físicos em situações que lhes façam sentido. Isso não exclui que em determinados momentos o professor faça breves apresentações e explicações ao grande grupo.

- Desenvolver competências científicas e tecnológicas como modelagem, argumentação a partir de evidências, validação e comunicação de resultados, fazendo uso intensivo de tecnologias de informação e comunicação, por exemplo, na simulação e modelagem computacionais e em laboratórios digitais.

- Na pesquisa em ensino, dar mais atenção à pesquisa translacional com participação de professores em serviço, ativos no ensino de Física na escola. Estimular a pesquisa em ensino dirigida a problemas reais da sala de aulas e apoiar a participação de professores nessa pesquisa. Valorizar a produção técnica.

- Não aceitar passivamente o ensino para a testagem. Física é muito mais do que fórmulas e respostas corretas. Ensino para a testagem é treinamento, é comportamentalismo, aquele em que o aluno deve dar a "resposta correta", ou seja, apresentar o comportamento esperado sem entrar na questão do sentido e do significado. 
- Mudar o currículo e o ensino na graduação em Física de modo que tenha mais Física, porém de uma perspectiva contemporânea, conceitual, epistemológica e de transposição didática. De nada serve apenas acrescentar novas disciplinas de Física na óptica de aulas expositivas e listas de problemas.

- Atualizar o currículo de Física do Ensino Médio, incorporando tópicos de Física moderna e contemporânea, não apenas para constar na lista de conteúdos, mas sim para que seja ensinada a Física de hoje usando situações da vida real, uma Física para a cidadania.

Não seria difícil acrescentar outros desafios para o ensino de Física na educação contemporânea. No entanto, os que foram apresentados são suficientes para conscientizar professores, gestores, pesquisadores de que esse ensino deve ser radicalmente modificado, sem perder a Física.

Como foi dito na introdução deste artigo, o ensino de Física tem longa tradição no Brasil. Muitas pesquisas foram feitas, muitas pós-graduações foram criadas, muitos recursos instrucionais foram produzidos e grandes professores pesquisadores dedicaram sua vida acadêmica a esse ensino deixando nele a sua marca.

Mas tudo isso parece ter sido obliterado por uma educação mercadológica, comportamentalista, treinadora para provas nacionais e internacionais. Certamente devem existir exceções em alguns contextos educativos do país, porém o mais comum é o ensino para testagem, ainda que maquiado com outras atividades. E a sociedade aceita passivamente, acriticamente, essa educação.

Nota

1 Neste texto os termos professor e aluno serão usados sem nenhuma alusão a gênero.

Referências

FINKEL, D. Teaching with your mouth shut. Portsmouth, NH: Boynton/Cook Publishers, 1999.

FREIRE, P. Pedagogia da autonomia. 36.ed. São Paulo: Paz e Terra, 2007.

MOREIRA, M. A. The relevance of physics knowledge for citizenship and the incoherence of physics teaching. In: LEITE, L.; DOURADO, L.; AFONSO, A. S.; MORGADO, S. Contextualizing teaching to improve learning. New York: Nova Science Publishers, 2017.

SCHWAB, J. The practical 3: translation into curriculum. School Review, v.81, n.4, p.501-22, 1973.

SKINNER, B. F. Tecnologia do ensino. São Paulo: Herder, 1972.

VERGNAUD, G. La théorie des champs conceptuels. Recherches en Didactique des Mathématiques, v.10, n.23, p.133-70, 1990.

WIEMAN, C. Grand challenges in science education. Transformation is possible if a university realy cares. Science, v.340, p.292-306, April 2013. 
RESUMO - A área de ensino de Física no Brasil tem longa tradição. A pesquisa e a pós-graduação em ensino de Física existem há décadas, assim como eventos nacionais da área. Muitos recursos instrucionais e projetos em ensino de Física já foram desenvolvidos. Revistas e publicações nessa área confirmam sua existência e consolidação. Paradoxalmente, no entanto, nos dias de hoje, o ensino de Física no Brasil está em crise, desatualizado, minimizado, desvalorizado. Este texto analisa criticamente vários aspectos desse ensino que levaram a essa crítica e apresenta alguns desafios a serem enfrentados para reverter tal situação e recuperar o ensino de Física no país. Sempre a partir da visão pessoal do autor e de sua larga experiência na área.

PALAVRAS-CHAVE: Ensino de Física, Ensino para testagem, Ensino para cidadania.

ABSTRACT - The area of Physics teaching in Brazil has a long tradition. Research and graduate programs in Physics teaching, as well as national conferences, have existed for decades. Many instructional materials and projects in Physics teaching have already been developed. Journals and publications in this area confirm that it exists and is consolidated. Paradoxically, however, nowadays Physics teaching in Brazil is in a serious crisis, outdated, minimized, underestimated. This text analyzes, critically, several aspects of Physics teaching that led to this crisis and presents some challenges that must be faced to change the situation and redeem Physics teaching in Brazil. The views presented here are always the author's personal outlook and derive from his extensive experience in this area.

KEYWORDS: Physics teaching, Teaching for testing, Physics for citizenship.

Marco Antonio Moreira é professor do Instituto de Física da Universidade Federal do Rio Grande do Sul (UFRGS). @ - moreira@if.ufrgs.br

Recebido em 16.8.2018 e aceito em 3.9.2018.

I Instituto de Física, Universidade Federal do Rio Grande do Sul, Porto Alegre, Rio Grande do Sul, Brasil. 